\title{
Reversal of Compromised Bond Strength of Bleached Enamel Using Cranberry Extract as an Antioxidant: an In Vitro Study
}

Anusha Egrula ${ }^{1}$, Pranitha V ${ }^{1}$, Dwijendra K. S ${ }^{1}$, Nagarjuna G ${ }^{1}$, Naseemoon Shaik ${ }^{1}$, Mohammadi Fatima

1. Pedodontics \& Preventive Dentistry, MNR Dental College and Hospital, Hyderabad, IND

Corresponding author: Pranitha V, pranithavallala@gmail.com

\begin{abstract}
Background and Objectives: Bleaching reduces the bond strength of enamel, if adhesive restorations are carried out immediately. Reversal of compromised bond strength of bleached enamel by application of antioxidant agents has been reported in the literature. The aim of the study is to assess the neutralizing effect of $6 \%$ cranberry (CB) solution on the bond strength of bleached enamel compared with that of $10 \%$ sodium ascorbate (SA) solution.
\end{abstract}

Materials and Methods: Enamel surfaces of 64 extracted human premolar teeth were randomly divided into four groups based on the antioxidant used. Further subgrouping was done in Groups II, III, and IV dividing each group into subgroup A and subgroup B of eight teeth each based on whether the bonding was performed immediately or after a delay of 14 days postbleaching respectively. Shear bond strength (SBS) of the specimens was measured using a Universal testing machine. The data were then tabulated and statistically analyzed using one-way ANOVA (analysis of variance) and Tukey's post-hoc parametric tests. A $\mathrm{p}$-value of $<0.05$ was considered statistically significant.

Results: The SBS measurements were compared among the four groups including the subgroups. The SBS was highest in the SA delayed bonding group and lowest in the bleached immediate bonding group.

Conclusion: A 10\% SA solution has proven superior to $6 \%$ CB solution in the reversal of compromised bond strength following bleaching.

Categories: Dentistry, Dentistry

Keywords: bleaching, hydrogen peroxide gel, $10 \%$ sodium ascorbate, $6 \%$ cranberry solution

\section{Introduction}

Received 10/30/2019

Review began 11/13/2019 Review ended 11/14/2019 Published 11/18/2019

(c) Copyright 2019 Eggula et al. This is an open access article distributed under the terms of the Creative Commons Attribution License CC-BY 3.0., which permits unrestricted use, distribution, and reproduction in any medium, provided the original author and source are credited.

Tooth bleaching has become one of the most popular esthetic dental treatments and also done to enhance a person's smile. It has been reported that the adhesion between the tooth surface and the bonding agent is hampered postbleaching [1-2]. The contributing factor for this reduced bond strength has been attributed to the oxygen free radicals accountable for the whitening effect; they adversely influence the penetration of the bonding agent into the tooth surface and inhibit the complete polymerization of the bonding agent [3].

Methods proposed to reverse the compromised bond strength of the resin material to bleached enamel are delay of $24 \mathrm{~h}$ to four weeks [4], removal of superficial layer of enamel [5], treatment of the bleached enamel with alcohol before the restoration [6], use of adhesives containing organic solvents [7], application of antioxidant agents $[3,8]$ before bonding the resin composite, and use of antioxidant incorporated bleaching agents [9].

The effect of cranberry (CB) as an antioxidant on bleached enamel has not been investigated so far. Hence, the present study is conducted with the aim to evaluate and compare the effects of $10 \%$ sodium ascorbate (SA) versus 6\% CB solution on the reversal of compromised bond strength of bleached enamel.

\section{Materials And Methods}

It is an in vitro study conducted at MNR Dental College and Hospital, Sangareddy, India. Some 64 sound extracted human premolar teeth with intact enamel surfaces without pretreatment with chemicals and devoid of developmental defects were included in the study. Fractured teeth and teeth with dental caries, attrition, abrasion, erosion, and previously restored or endodontically treated teeth were excluded from the study. The teeth were cleaned to remove any residual tissue tags. The roots were amputated from the crowns at the cementoenamel junction using slow speed diamond disc under copious water spray. The teeth were then mounted in cold-cure acrylic resin using Teflon mold, with the buccal surface facing upwards. Some 16 teeth were sampled as Group I $(n=16)$ which served as the positive control group and did not receive any bleaching treatment. Remaining 48 teeth were equally divided into three groups (Groups II, III, and IV) 


\section{Cureus}

based on the type of antioxidant used after bleaching. The groups were further divided into subgroups A (immediate bonding) and B (delayed bonding after two weeks) based on the storage period before composite build-up. Each subgroup consisted of eight teeth (Figure 1).

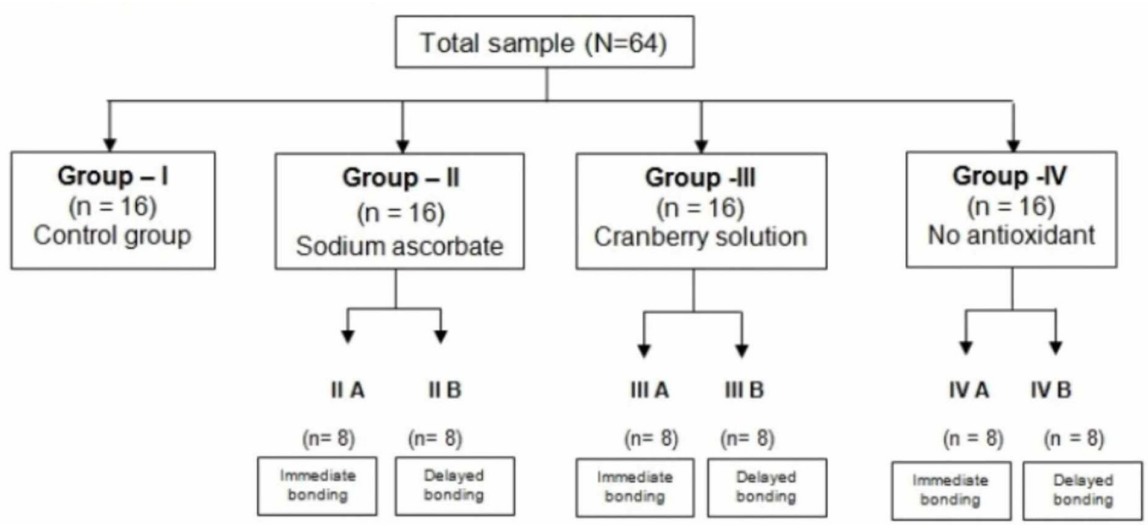

FIGURE 1: Experimental design.

\section{Bleaching procedure}

Bleaching gel containing 40\% hydrogen peroxide (Opalescence boost, Ultradent products, Inc, South Jordan UT) was placed on the enamel surface of sample for 20 min according to the manufacturer's instructions (Figure 2). The bleaching gel was then completely rinsed off with water.

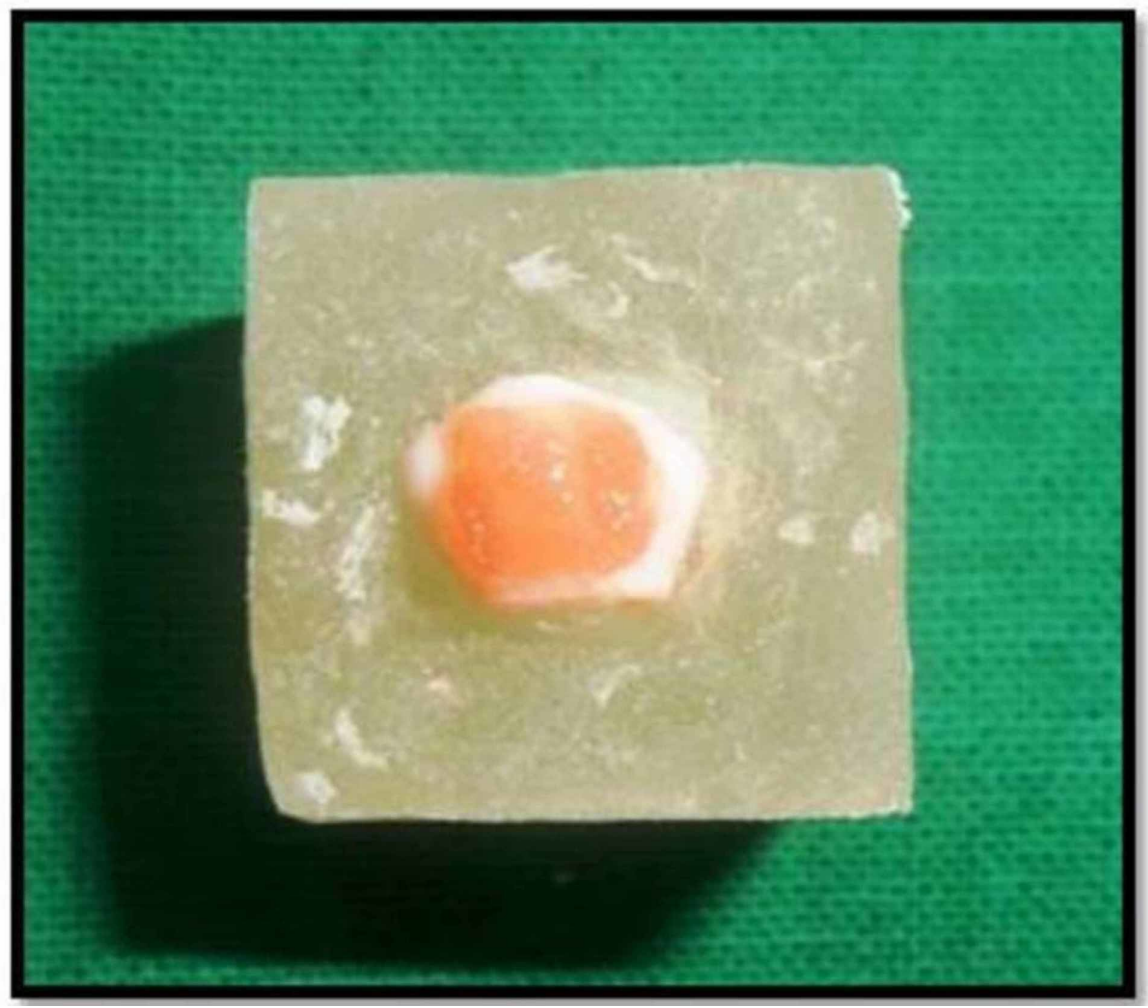

FIGURE 2: Application of $40 \%$ hydrogen peroxide gel.

\section{Preparation of solutions}

Two solutions were prepared for this study:

1) $10 \mathrm{~g}$ of SA (Limcee, Abbott healthcare Pvt. Ltd, India) was dissolved in $100 \mathrm{~mL}$ of distilled water to make $10 \%$ SA solution. 


\section{Cureus}

2) $6 \mathrm{~g}$ of CB extract (TracfreeTM, Zydusnutriva, Cadila healthcare Ltd., India) in the form of powder was collected from the tablets and dissolved in $100 \mathrm{~mL}$ of distilled water to make $6 \% \mathrm{CB}$ extract solution.

The respective samples were immersed in 10\% SA and 6\% CB extract solution for 10 min (Figure 3A,B) following the bleaching process and then the specimens were rinsed with distilled water and dried with compressed air.

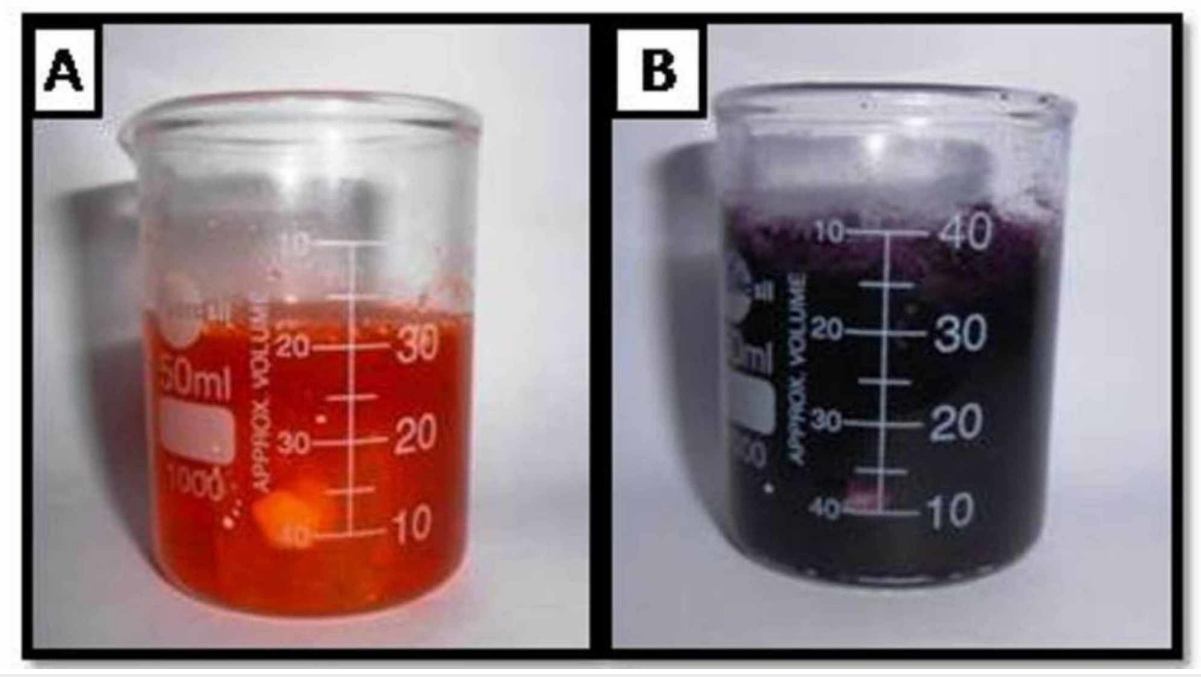

FIGURE 3: A. Immersion of bleached specimens in $10 \%$ sodium ascorbate solution. B. Immersion of bleached specimens in $6 \%$ cranberry solution.

\section{Bonding procedure}

All of the specimens were etched with $37 \%$ phosphoric acid gel (D-tech Dental technologies, Pune, India) for $15 \mathrm{~s}$ and then rinsed with water for $20 \mathrm{~s}$ and air dried for $5 \mathrm{~s}$. Adhesive (Prime \&Bond ${ }^{\circledR}$ NT Nano-technology dental adhesive, Dentsply, USA) was then applied, gently air thinned, and light cured for $10 \mathrm{~s}$.

A split-mold metal casing ( $3 \mathrm{~mm}$ in diameter and $5 \mathrm{~mm}$ in height) was used to maintain uniformity in composite build-up. The casing was placed on adhesive-applied enamel surfaces; composite (Filtek Z350, 3M ESPE, Dental Products, India) was then filled into the hole in layers and each layer was light cured according to the manufacturer's instructions. After polymerization, mold was removed and specimens were placed in distilled water for $24 \mathrm{~h}$.

After 24 hours all specimens were tested for shear bond strength (SBS) in shear mode (using a steel knife edge shearing rod) using a Universal testing machine (Dak System Inc.'s U.T.M, India) at a crosshead speed of $0.5 \mathrm{~mm} / \mathrm{min}$ (Figure 4). SBS values were expressed in mega pascal (MPa).

The data were subjected to parametric tests -- one way ANOVA (analysis of variance) for multiple group comparison of SBS followed by Tukey's post-hoc test for group wise comparison depending on the normality of data and p-value $(<0.05)$ was considered statistically significant. 


\section{Cureus}

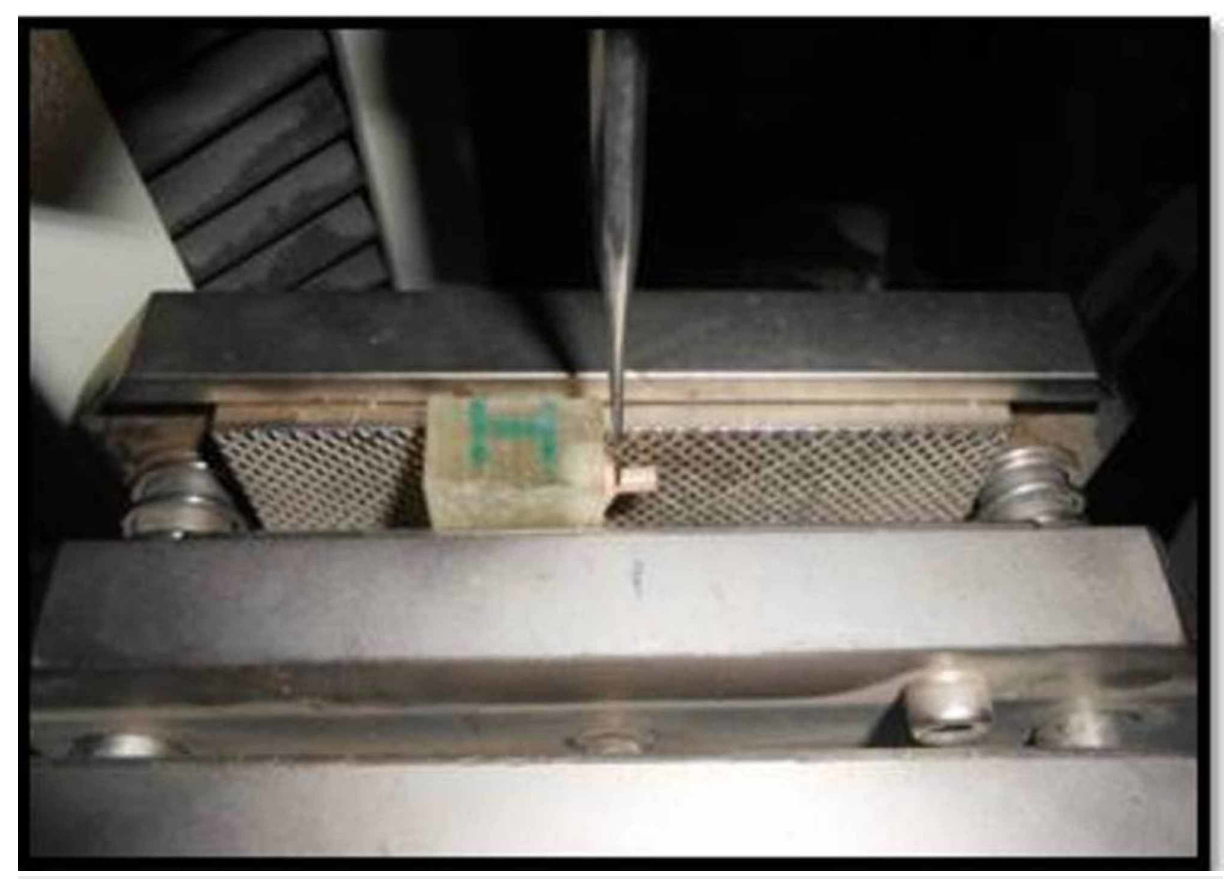

FIGURE 4: Shear bond strength testing by Universal testing machine.

\section{Results}

The SBS measurements were compared among the four groups including the subgroups and are shown in Figure 5.

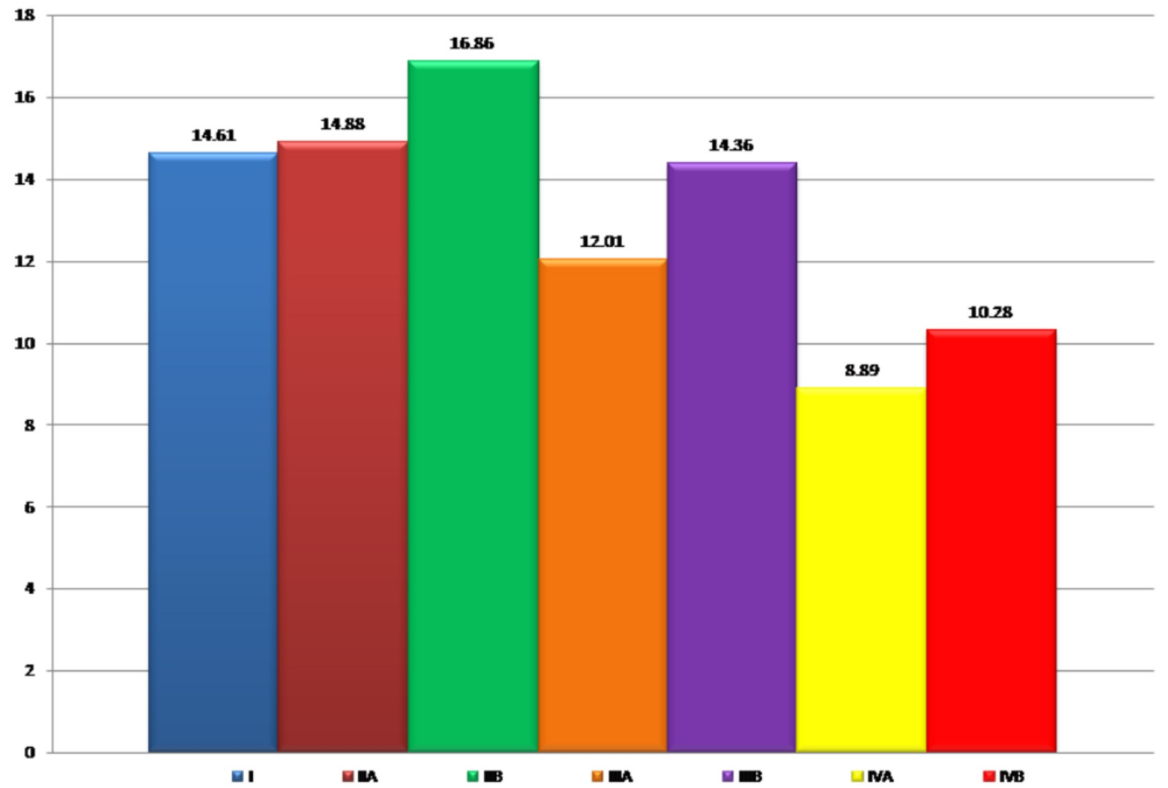

FIGURE 5: Inter-group comparison of mean shear bond strength (MPa).

The SBS was highest in the SA delayed bonding group and lowest in the bleached immediate bonding group. A statistically significant difference was found between the control group and the bleached group $(\mathrm{p}=0.006)$. Among the subgroups of A, Group IIA showed the highest mean SBS value, in the order of Group IIA (Bleaching $+10 \% \mathrm{SA}+$ Immediate bonding) $>$ IIIA (Bleaching+6\% CB+Immediate bonding) > IVA (Bleaching+Immediate bonding). Among the subgroups B, Group IIB had the highest SBS; in the order of Group IIB (Bleaching+10\% SA+delayed bonding) > Group IIIB (Bleaching+6\% CB+Delayed bonding) > Group IVB (Bleaching+Delayed bonding) (Table 1). In the inter-group comparison, the highest mean value of SBS 


\section{Cureus}

was recorded for Group IIB in the order of IIB > IIA > I > IIIB > IIIA > IVB > IVA. However, the difference between the antioxidant groups was statistically insignificant (Table 2).

\begin{tabular}{|c|c|}
\hline Inter-group comparison & $\mathrm{p}$-value \\
\hline I vs IIA & $>0.99 *$ \\
\hline | vs IIB & $0.737^{\star}$ \\
\hline I vs IIIA & $0.493^{*}$ \\
\hline I vs IIIB & $>0.99^{*}$ \\
\hline I vs IVA & $0.006^{* *}$ \\
\hline I vs IVB & $0.201^{*}$ \\
\hline IIA vs IIB & $0.522^{\star}$ \\
\hline IIA vs IIIA & $0.062^{\star}$ \\
\hline IIA vs IIIB & $0.995^{*}$ \\
\hline IIA vs IVA & $<0.001^{\star \star}$ \\
\hline IIA vs IVB & $0.072^{\star}$ \\
\hline IIB vs IIIA & $0.022^{\star \star}$ \\
\hline IIB vs IIIB & $0.480^{\star}$ \\
\hline IIB vs IVA & $<0.001^{\star *}$ \\
\hline IIB vs IVB & $0.015^{\star \star}$ \\
\hline IIIA vs IIIB & $0.389^{*}$ \\
\hline IIIA vs IVA & $0.066^{\star}$ \\
\hline IIIA vs IVB & $0.888^{*}$ \\
\hline IIIB vs IVA & $0.002^{\star \star}$ \\
\hline IIIB vs IVB & $0.172^{\star}$ \\
\hline IVA vs IVB & $0.941^{*}$ \\
\hline
\end{tabular}

TABLE 1: Inter-group comparison of level of significance.

*Not significant; **Significant 


\section{Cureus}

\begin{tabular}{|l|l|l|}
\hline Group & Mean (MPa) & Standard deviation \\
\hline I & 14.61 & 3.72 \\
\hline IIA & 14.88 & 0.91 \\
\hline IIB & 16.86 & 2.79 \\
\hline IIIA & 12.01 & 2.12 \\
\hline IIIB & 14.36 & 2.29 \\
\hline IVA & 8.89 & 1.65 \\
\hline IVB & 10.28 & 3.55 \\
\hline
\end{tabular}

TABLE 2: Inter-group comparison of mean shear bond strength (MPa).

\section{Discussion}

Our results proved a decrease in SBS of composite resin to enamel immediately after bleaching, which was statistically significant when compared with the control group and the antioxidant groups.

Many studies have shown that the inclusion of peroxide ions may be reversed by the use of SA as an antioxidant [10-18]. Hence in this study, $10 \%$ solution of SA with application time of $10 \mathrm{~min}$ was preferred to be adequate for clinical application of the antioxidant in solution form.

Etched appearance of enamel surfaces after ascorbic acid usage in bleached enamel specimens demonstrated super etching of the already bleached enamel surface under scanning electron microscope (SEM) [19]. Despite the wide-spread application of SA as an antioxidant, Savadi et al. [20] showed that the cumulative effect of SA and bleached material may lead to increased retention of pathogenic microorganisms in enamel surfaces. Usage of flavonoid-rich CB with proanthocyandinins as antioxidants presents as a viable alternative.

Treatment with $6 \% \mathrm{CB}$ solution enhanced the bond strength of bleached enamel when compared to the bleached group not treated with any antioxidants, both when bonding was performed immediately and after storage in distilled water for two weeks following bleaching .

Both $6 \%$ CB solution and $10 \%$ SA solutions were found to be effective antioxidants with latter being more effective than the former but not statistically significant.

In Group IVB, the bond strength was higher compared to Group IVA. This could be attributed to the partial loss of oxygen diffusion layer over time at the tooth and composite interface [21]. Group II showed the highest bond strength among the study groups; both when bonding was performed immediately as well as after two weeks. Group III showed increased bond strength compared to Group IV; it had lesser bond strength than Group II and Group I.

Cranberry with proanthocyanidin with molecular weight ranging from 500 to $3000 \mathrm{~g} / \mathrm{mol}$ had lesser penetration and bond strength when compared to SA with molecular weight $198.11 \mathrm{~g} / \mathrm{mol}$.

Moreover, different findings might be due to different antioxidant application methods. In previous studies $[4,22]$ during the 10 -min treatment period the antioxidant solution was continuously refreshed and the enamel surface was agitated, which can enhance the antioxidant effect on the bleached enamel surface while in the present study the specimens were immersed in the antioxidant solution for $10 \mathrm{~min}$ as done by Lai et al. [3]. More recently a study conducted by Ismail et al. [18] concluded that an application of higher concentration of SA for a shorter time would reverse the negative effects of bleaching agents on bonding.

\section{Conclusions}

In our findings $10 \% \mathrm{SA}$ has proven to be superior compared to $6 \% \mathrm{CB}$ solution in reversing the bond strength of composite resin to bleached enamel. We conclude that $6 \% \mathrm{CB}$ solution can also be used as a viable antioxidant in the reversal of compromised bond strength of bleached enamel. Future studies are required to authenticate our observations.

\section{Additional Information}




\section{Disclosures}

Human subjects: Consent was obtained by all participants in this study. MNR Dental College \& Hospital ethical commitee issued approval ECR/227/indt/TG/2013. The ethical committee constitute by MNR Dental college and Hospital sangareddy has approved the dissertation titled -Reversal of Compromised Bond Strength of Bleached Enamel Using Cranberry Extract as an Antioxidant-an invitro study. . Animal subjects: All authors have confirmed that this study did not involve animal subjects or tissue. Conflicts of interest: In compliance with the ICMJE uniform disclosure form, all authors declare the following: Payment/services info: All authors have declared that no financial support was received from any organization for the submitted work. Financial relationships: All authors have declared that they have no financial relationships at present or within the previous three years with any organizations that might have an interest in the submitted work. Other relationships: All authors have declared that there are no other relationships or activities that could appear to have influenced the submitted work.

\section{References}

1. Shah V, Patel M, Bhavsar B: An in vitro comparative evaluation of various newer bonding agents on bond strength of bleached enamel treated with an antioxidant. IOSR-JDMS. 2018, 17:50-53.

2. Titley KC, Torneck CD, Ruse ND, Krmec D: Adhesion of a resin composite to bleached and unbleached human enamel. J Endod. 1993, 19:112-115.

3. Lai SC, Tay FR, Cheung GS, Mak YF, Carvalho RM, Wei SH: Reversal of compromised bonding in bleached enamel. J Dent Res. 2002, 81:477-481. 10.1177/154405910208100709

4. Bulut H, Turkun M, Kaya AD: Effect of an antioxidizing agent on the shear bond strength of brackets bonded to bleached human enamel. Am J Orthod Dentofacial Orthop. 2006, 129:266-272. 10.1016/j.ajodo.2004.03.043

5. Cvitko E, Denehy GE, Swift EJ Jr, Pires JA: Bond strength of composite resin to enamel bleached with carbamide peroxide. J Esthet Dent. 1991, 3:100-102.

6. Barghi N, Godwin JM: Reducing the adverse effect of bleaching on composite-enamel bond . J Esthet Dent. 1994, 6:157.

7. Kalili T, Caputo AA, Mito R, Sperbeck G, Matyas J: In vitro toothbrush abrasion and bond strength of bleached enamel. Pract Periodontics Aesthet Dent. 1991, 3:22-24.

8. Manoharan M, Shashibushan KK, Poornima P, Naik SN, Patil D, Shruthi AS: Effect of newer antioxidants on the bond strength of composite on bleached enamel. J Indian Soc Pedod Prev Dent. 2016, 34:391-396. 10.4103/0970-4388.191430

9. Nair M, Nesamani R, Sanjeev K, Sekar M, Renganathan S: Effect of single and two step application of antioxidant incorporated bleaching agents on bond strength of resin composite and surface changes in enamel. Biol Med (Aligarh). 2016, 8:348.

10. Beltagui S, Bakry S, Hussain S, Mohy El Din M: Effect of antioxidant treatment and delayed bonding on shear bond strength of porcelain laminate veneers bonded to bleached enamel (in vitro study). Int J Dent Oral Heal. 2017, 3:2-13. 10.25141/2471-657X-2017-2.0013

11. Paul P, Hannah RH, Balagopal S: The effect of hydrogel and solution of sodium ascorbate on the bond strength of bleached enamel. J Conserv Dent. 2007, 10:43-47. 10.4103/0972-0707.42289

12. Fine AM: Oligomeric proanthocyanidin complexes: history, structure, and phytopharmaceutical applications. Altern Med Rev. 2000, 5:144-151.

13. De Sousa Ferreira R, Padua Albuquerque do Nascimento E: Sodium ascorbate use In bleached teeth . Rev Odonto Cienc. 2016, 31:176-180.

14. Titley KC, Torneck CD, Ruse ND: The effect of carbamideperoxide gel on the shear bond strength of a microfilm resin to bovine enamel. J Dent Res. 1992, 71:20-24. 10.1177/00220345920710010301

15. Vidhya S, Srinivasulu S, Sujatha M, Mahalaxmi S: Effect of grape seed extract on the bond strength of bleached enamel. Oper Dent. 2011, 36:433-438.

16. Subramonian R, Mathai V, Christaine Angelo JB, Ravi J: Effect of three different antioxidants on the shear bond strength of composite resin to bleached enamel: an in vitro study. J Conserv Dent. 2015, 18:144-148.

17. Danesh-Sani SA, Esmaili M: Effect of $10 \%$ sodium ascorbate hydrogel and delayed bonding on shear bond strength of composite resin and resin-modified glass ionomer to bleached enamel. J Conserv Dent. 2011, 14:241-246. 10.4103/0972-0707.85799

18. Isamil EH, Kilinc E, Hardigan PC, Rothrock JK, Thompson JY, Garcia Godoy C: Effect of two minute application of $35 \%$ sodium ascorbate on composite bond strength following bleaching. J Contemp Dent Pract. 2017, 18:874-880.

19. Muraguchi K, Shigenobu S, Suzuki S, Tanaka T: Improvement of bonding to bleached bovine tooth surfaces by ascorbic acid treatment. Dent Mater J. 2007, 26:875-881. 10.4012/dmj.26.875

20. Savadi OS, Alizadeh OP, Soroush MH, Ajami A, Beheshtirouy M, Pouranghi FA: Effect of $10 \%$ sodium ascorbate on Streptococous mutans adherence to bovine enamel bleached with carbamide peroxide. Afric J Biotechnol. 2010, 4:5419-5422.

21. Arumugam MT, Nesamani R, Kittappa K, Sanjeev K, Sekar M: Effect of various antioxidants on the shear bond strength of composite resin to bleached enamel: an in vitro study. J Conserv Dent. 2014, 17:22-26. 10.4103/0972-0707.124113

22. Bulut H, Kaya AD, Turkun M: Tensile bond strength of brackets after anti-oxidant treatment on bleached teeth. Eur J Orthod. 2005, 27:466-471. 10.1093/ejo/cji044 